\title{
Aprendendo sobre avaliação pesquisando o conteúdo de provas escritas: relato de uma experiência no Curso de Biologia da Universidade Católica Dom Bosco
}

\begin{abstract}
Learning about evaluation researching the content of written tests: an experience report in the Course of Biology of the Universidade Católica Dom Bosco
\end{abstract}

\author{
Cássia Santos Camillo 1 \\ Esther Campagna BertazzonI ${ }^{1}$ \\ Gislaine Delfino Silva ${ }^{1}$ \\ LUCIANA MARIA BRITO ${ }^{1}$ \\ Maikel da Silva Ferreira Luiz ${ }^{1}$ \\ Patrícia Tostes Palma ${ }^{1}$ \\ TÂmara Santos ${ }^{1}$ \\ Tatyane do Socorro Soares Brasil ${ }^{1}$ \\ Wanessa Barbosa Santana ${ }^{1}$ \\ Maria Aparecida de Souza Perrelli ${ }^{2}$
}

${ }_{1}^{1}$ Graduados do Curso de Biologia da Universidade Católica Dom Bosco, Campo Grande, MS.

2 Doutora em Educação para a Ciência, Professora da Universidade Católica Dom Bosco. cidaperrelli@yahoo.com.br. 


\section{Resumo Abstract}

A formação do professor inclui, dentre outros aspectos, a instrumentação para a pesquisa em educação e a avaliação do ensino e da aprendizagem. Cientes da complexidade dessas questões, os graduandos do ano de 2005 do curso de Biologia da Universidade Católica Dom Bosco, por meio da disciplina de Estágio Supervisionado, foram desafiados a pesquisar e refletir sobre o tema "ava-

liação" mediante o desenvolvimento de um projeto de pesquisa que analisou o conteúdo de provas de Biologia aplicadas em escolas da cidade de Campo Grande, MS. As provas foram analisadas de acordo com a estruturação das ques-

tões, as habilidades exigidas e o nível de complexidade. Das 736 questões analisadas, a maioria foi estruturada na forma de questões objetivas. Tanto as questões objetivas quanto as discursivas priorizaram a repetição/memorização dos conteúdos. Houve questões que apresentaram falhas técnicas na sua elaboração. As questões foram referenciadas em uma perspectiva normativa e não formativa da avaliação, enfocando apenas o aluno, não remetendo à avaliação do trabalho do professor. A experiência relatada sinaliza para a importância de formar o professor para a avaliação e como pesquisador de sua própria prática.

\section{PALAVRAS-Chave}

avaliação

ensino de Biologia formação do professor
Teacher training includes, among other aspects, instrumentation for research in education and the evaluation of the process of teaching and learning. Aware of the complexity that involves those subjects, undergraduates of 2005 term of Biology Course at the Universidade Católica Dom Bosco, through the discipline of Supervised Apprenticeship, were challenged to research and to reflect upon the theme "evaluation" through the development of a research project that analyzed the content of the Biology's tests applied at schools of the city of Campo Grande, Mato Grosso do Sul, Brasil. The tests were analyzed according to the structuring of subjects, demanded abilities and the level of complexity. From 736 analyzed questions, most were objectively structured. Both questions in objective and subjective formulations have priorized memory related skills. It had questions that they had presented imperfections techniques in its elaboration. The questions were framed in a normative and not formative perspective of the evaluation process, focusing only the student, not taking into account an evaluation of the teacher's work. The reported experience points towards the importance of training teachers to evaluation and also as researcher of their own practice.

\section{KEY WORDS}

evaluation teaching of Biology teacher training 


\section{InTRODuÇão}

A avaliação da aprendizagem é, e sempre foi, um desafio para todos os que lidam com Educação, embora se tenha dificuldade em esclarecer o verdadeiro papel exercido pelas avaliações no processo de aprendizagem (RAMOS, 1987). Para Ficher (2002), é impossível pensar a escola, ou pensar a educação em suas diferentes instâncias sem considerar as modalidades de avaliação e seus dispositivos de poder. Deve-se percebê-la como um poder que circula entre os pontos múltiplos do ambiente escolar, ora identificado na figura do aluno, ora na do professor.

De acordo com Sant'Anna (1995), a avaliação escolar é o termômetro que permite confirmar o estado em que se encontram os elementos envolvidos no contexto educacional. Ela tem um papel altamente signnificativo no processo de educação, uma vez que não pode ser vista apenas como uma forma de avaliar o aluno, mas também para que o professor possa rever sua prática de ensino, modificando-a quando necessário.

Para Rodrigues (1992) a avaliação é uma interferência fundamental do professor, no processo educativo, o que exige saber quando, como e por quê deve-se interferir. Muitos professores usam a avaliação como uma ameaça e até se vangloriam de reprovar a classe toda, levando os alunos e familiares ao desespero. Na escola, a avaliação tem uma longa tradição de funcionar como estratégia de seleção, exclusão e de rotulação de alunos. Para Luckesi (1995), a avaliação que se pratica na escola é a avaliação da culpa, na qual as notas são usadas para fundamentar necessidades de classificação de alunos. Estas comparam desempenhos e não objetivos que se deseja atingir. As classificações escolares, de acordo com Perrenoud (2000), remetem à idéia de fracasso, que só existe no âmbito de instituições que têm o poder de julgar e classificar o aluno. O fracasso é, portanto, sempre relativo a uma cultura escolar definida, é um julogamento institucional.

Na avaliação, utilizada unicamente como "medida", ranço do positivismo, usam-se largamente como instrumentos as provas escritas. Está associada, em grande parte, a um papel normativo e não formativo. Hadji (2001) assinala que, a passagem de uma avaliação 
normativa para a formativa, implica, necessariamente, uma modificação das práticas do professor em compreender o seu aluno como ponto de partida e de chegada. Seu progresso só pode ser percebido quando comparado com ele mesmo: Como estava? Como está? As ações desenvolvidas entre as duas questões compõem a avaliação formativa.

Para Sant'Anna (1995) há três tipos de avaliação, a saber: diagnóstica, formativa e somativa. Aydos et al. (2004) referem a estes tipos como três momentos de avaliação. A diagnóstica, também chamada de inicial, é aquela que detecta a presença ou ausência de conhecimento e habilidades. Já a formativa visa determinar o resultado da aprendizagem do aluno, informando possíveis deficiências no processo ensino-aprendizagem. A somativa, por sua vez, tem o objetivo de classificar os alunos em níveis de aproveitamento.

Qualquer que seja o momento, pode-se dizer, de acordo com Sant'Anna (1995), que só será eficiente e eficaz se ocorrer de forma interativa entre o professor e o aluno, ambos caminhando na mesma direção, em busca dos mesmos objetivos. Nessa compreensão, Perrenoud (1999) sinaliza que a avaliação permite determinar quanto e em que nível os objetivos estão sendo atingidos. Para alcançar esses objetivos, Libâneo (1994) afirma que é necessário o uso de instrumentos e procedimentos de avaliação adequados.

Freitas (1995), ao destacar o resultado de algumas pesquisas feitas sobre avaliação, assinala que os professores concebem a avaliação como meio de verificar se o aluno aprendeu o conteúdo, verificar os pontos fortes e fracos para atuar/mudar método, avaliar nível de desempenho dos alunos, promover o desenvolvimento do aluno, verificar se o aluno atingiu os objetivos, verificar se o aluno tem os pré-requisitos, além de cumprir formalidades e conceituar o aluno. As técnicas mais usadas pelos professores para avaliar são trabalhos (em classe e fora dela), observação de desempenho, provas escritas, participação e interesse do aluno. Destaca, ainda, que cerca de $80 \%$ dos professores não elaboram critérios para correção das avaliações antes de efetuá-Ias, 75\% dos professores não comunicam aos alunos os critérios de avaliações. As pesquisas mostram também que há discrepância entre 
o que se ensina e o que se cobra. As avaliações são percebidas pelos alunos como um meio de abuso de poder pelos professores, que estes as usam para impor disciplina, que demonstram tendenciosidade ao avaliar os alunos e que não usam a avaliação para reverter as falhas, o que indica que a avaliação é vista de modo unilateral, isto é, só o aluno é avaliado.

Para Gimeno-Sacristán (1995), quando avalia, o professor o faz a partir de suas concepções, seus valores, expectativas e também a partir das determinações do contexto institucional. Muitas vezes, nem ele próprio tem muita clareza ou mesmo sabe explicitar estes dados considerados na avaliação dos alunos.

As avaliações realizadas nas escolas decorrem, portanto, de concepções diversas, das quais nem sempre o professor tem clareza e consciência dos seus fundamentos. Ele acaba envolvido pelas determinações do contexto institucional que, na maior parte das vezes, apóia-se na avaliação classificatória com a pretensão de verificar aprendizagem ou competências por meio de medidas, de quantificações.

Apesar de tudo que se tem discutido, ainda hoje a avaliação escolar tem sido usada como meio de testar e medir os acertos e erros dos alunos. Na prática, avaliar está associado a fazer provas, atribuir notas, calcular-se as médias e aprovar ou não o aluno a partir destas. Nesse sentido, Hoffmann (2000) destaca que as notas/conceitos dados pelos professores aos alunos são uma medida que equivale ao mesmo que medir extensão, volume e outros atributos dos objetos e fenômenos. Em outras palaøras, para a autora, "[...] conceber e nomear o 'fazer testes', o ‘dar notas', por avaliação, é uma atitude simplista e ingênua! Sionnifica reduzir o processo avaliativo, de acompanhamento e ação com base na reflexão, a parcos instrumentos auxiliares desse processo, como se nomeássemos por bisturi um procedimento cirúrgico" (HOFFMANN, 2000, p. 53).

Ainda que lance mão de estratégias diversas - observação, provas orais ou escritas, individuais ou em grupo, trabalhos de pesquisa, relatórios, seminários, dentre outras - o professor acaba por situar a avaliação simplesmente como medida da retenção de informações 
sobre conceitos e raramente aborda as dimensões procedimental e atitudinal do processo de aprendizagem. Nesse aspecto, Rodrigues (1992) assinala que a avaliação se apresenta como um jogo de valorização da memória, dando privilégio ao aluno memorizador, sem levar em consideração outras tendências, aptidões e habilidades específicas.

\section{Metodologia}

A pesquisa foi desenvolvida no ano de 2005, no âmbito da disciplina de Estágio Supervisionado, do oitavo (último) semestre do Curso de Biologia da Universidade Católica Dom Bosco, em Campo Grande, MS. A idéia da pesquisa surgiu no contexto das discussões acerca do tema "avaliação escolar" e durante o estágio de docência no Ensino Médio em escolas da rede pública e privada. Foi solicitado aos graduandos, pela professora da disciplina, que obtivessem uma cópia de todas as provas escritas de Biologia elaboradas pelos professores regentes das escolas em que estagiavam. Os conteúdos das questões seriam analisados e discutidos, coletivamente, em sala de aula.

Os critérios para análise foram definidos em sala de aula, e diziam respeito à estruturação da prova nos seguintes aspectos: os tipos de questões (se se tratavam de questões objetivas, discursivas etc), a análise técnica das questões formuladas (se as questões eram claras, ambíguas, óbvias, se havia pistas gráficas etc), as habilidades e às operações de pensamento mobilizadas.

Para analisar o nível de raciocínio ou as operações de pensamento mobilizadas no desenvolvimento das questões foram definidos três níveis. O nível 01 corresponderia às questões que priorizavam a "repetição", na qual o aluno deve apenas mencionar ou discorrer sobre aquilo que já havia sido tratado na sala de aula; o nível 02 reportaria à "integração", isto é, o aluno deveria relacionar os conhecimentos adquiridos e organizar seu raciocínio para solucionar uma questão em nova situação proposta; o nível 03, definido como o da "criação", seria aquele a partir do qual o aluno relacionaria o que foi estudado 
para simular, levantar hipóteses, solucionar problemas reais e/ou imaginários, além de prever situações e problemas futuros.

As questões deveriam, ainda, ser analisadas com relação às habilidades exigidas, visando compará-las com as habilidades necessárias para a construção do pensamento científico.

\section{Resultados e discussões}

De posse do material recolhido, foram somadas as questões de todas as provas obtidas, totalizando-se 736 questões a serem analisadas. Numa primeira triagem, foi possível dividir as questões em dois grupos - objetivas e discursivas. No primeiro grupo foram incluídas questões do tipo múltipla escolha, respostas curtas (completar lacunas), certo ou errado e associação (relacionar colunas). As questões discursivas foram divididas em três subgrupos: questões dissertativas abertas (envolvendo tema amplo), dissertativas restritivas (tema pontual) e subjetivas (requer a opinião do aluno).

Nessa triagem, observou-se que um total de 202 questões $(27,44 \%)$ eram cópia de questões de vestibular. Parece que há uma prática corrente nessa direção, indicando que o ensino médio estaria imbuído da idéia de transmitir ao aluno fórmulas, conteúdos e estratégias para responder questões típicas de um determinado exame de seleção para o curso superior, e não para compreender o assunto e/ou preparar o estudante para a vida acadêmica.

Quanto à estruturação das questões, observou-se que 57,88\% eram de múltipla escolha, 23,64\% eram dissertativas restritivas e 11,6\% dissertativas abertas, 3,94\% de questões de completar lacunas, 1,63\% de questões para marcar certo ou errado e 1,22\% do tipo relacionar a segunda coluna de acordo com a primeira (Figura 1). 


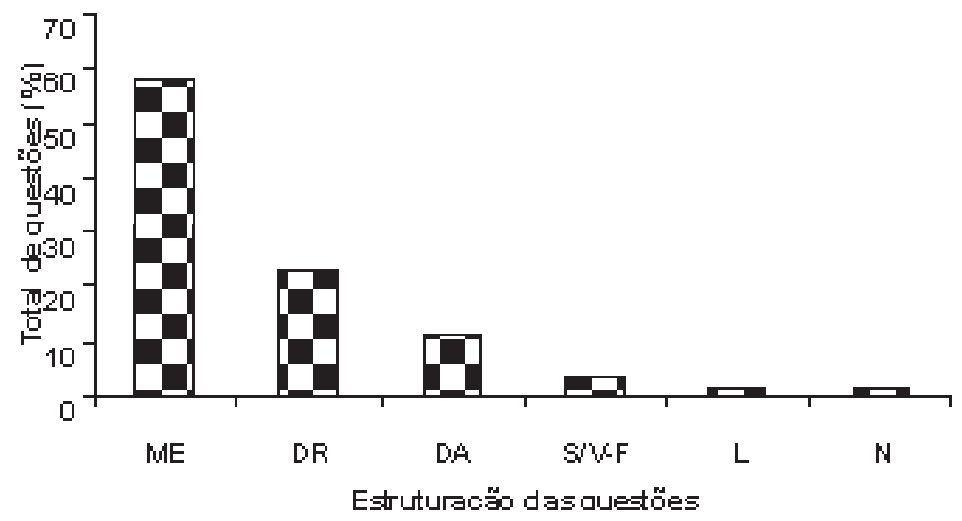

Figura 1. Percentagem de questões quanto à estruturação das questões. $(\mathrm{ME}=$ Múltipla Escolha, $\mathrm{DR}=$ Dissertativa restrita, $\mathrm{DA}=$ Dissertativa Aberta, $\mathrm{S} / \mathrm{V}-\mathrm{F}=$ Somatório Verdadeiro-Falso, $\mathrm{L}=$ Lacunas, $\mathrm{N}=$ Numerar).

Embora existam muitas críticas às questões objetivas (múltipla escolha, completar lacunas, numerar colunas etc), elas ainda perfazem mais de $60 \%$ das questões aplicadas pelos professores. Machado (1991) denomina tais questões como "questões de respostas curtas" e cita, dentre as críticas comumente realizadas, o fato de facilitarem o "chute", de modo que nem sempre permitem avaliar se o aluno sabe o que foi solicitado a demonstrar. Para esse autor, as questões dissertativas deveriam ser mais utilizadas pelos professores, pois estimulam as habilidades mentais mais elevadas, avaliam o uso da língua escrita, são úteis para descobrir os processos mentais que o estudante utiliza, entre outras vantagens da dissertação em relação às respostas curtas.

No intuito de verificar se as questões dissertativas estariam, de fato, relacionadas com o estímulo de habilidades mentais mais elevadas, foram avaliadas as 253 questões de caráter discursivo. Destas, $58,49 \%$ solicitavam ao aluno para explicar, $14,62 \%$ para definir, $11,06 \%$ para comparar ou diferenciar. Demais habilidades como citar, calcular, re-escrever e classificar somaram 11,85\%, enquanto as habilidades que remetiam ao uso de operações mentais mais complexas, como justificar, opinar, supor e analisar somaram apenas 3,93\% (Figura 2). 


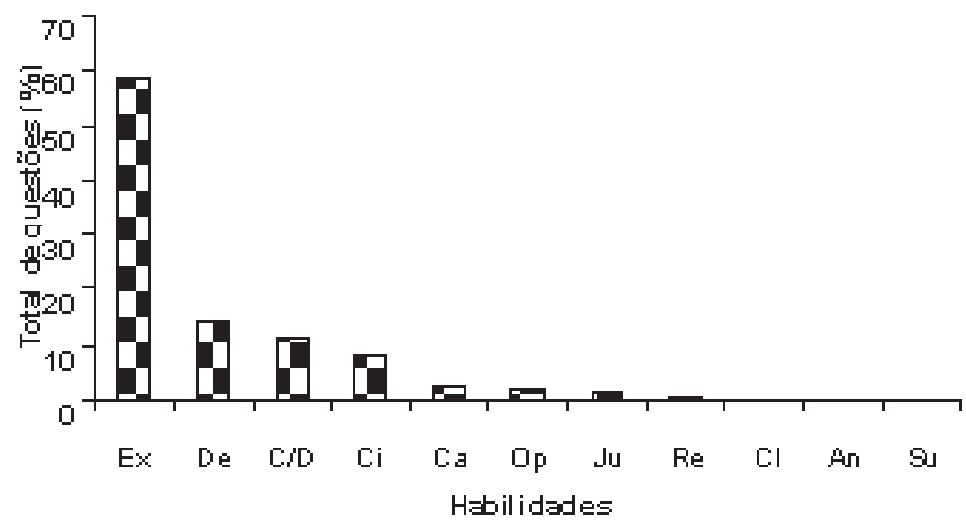

Figura 2. Percentagem de questões quanto às habilidades exigidas. (Ex $=$ Explicar, $\mathrm{De}=$ Definir; $\mathrm{C} / \mathrm{D}=$ Comparar $/$ Diferenciar, $\mathrm{Ci}=\mathrm{Citar}, \mathrm{Ca}=$ Calcular, $\mathrm{Op}=\mathrm{Opi}-$ nar, Ju=Justificar, $\mathrm{Re}=$ Reescrever, $\mathrm{Cl}=$ Classificar, $\mathrm{Na}=$ Analisar, $\mathrm{Su}=$ Supor).

Nas habilidades exigidas pelas questões dissertativas, foram analisadas as palavras de ordem ou palavras-chaves de cada questão formulada, tanto pelos professores quanto nas questões copiadas de vestibular. Segundo Machado (1991) tais palavras são de suma importância para a organização das respostas.

Na nossa compreensão, as palaøras-chaves utilizadas na formulação das perguntas mobilizam as operações mentais de nível 1 (repetição, memorização) quanto ao raciocínio exigido do aluno. Nas questões que solicitam ao aluno que "complete", "defina”, "explique", por exemplo, espera-se que as respostas sejam curtas, menos elaboradas, mais ou menos idênticas ao que foi ensinado. Quando se deseja ir mais além, utilizam-se questões que envolvam habilidades como supor, comparar situações, formular hipóteses, que demandam um raciocínio mais elaborado e o senso crítico.

Verificou-se que essas questões priorizavam a repetição/memorização quando ordenavam ao aluno que "explique" (por exemplo: como se explica a condução da seiva bruta?), "defina” (defina cariótipo, homozigoto, heterozigoto, diplóide, haplóide), “cite” (cite a primeira lei de Mendel), "classifique” (classifique os animais quanto à presença de notocorda), "calcule" (qual o número de cromossomos obtidos após a meiose e a mitose das células descritas abaixo), pois, 
remetiam a algo que, muito provavelmente fora explicado, definido, citado, classificado etc em sala de aula tal qual o exigido nas provas. Até mesmo as questões que ordenavam "compare" ou "diferencie" (por exemplo: diferencie sangue venoso e arterial) provavelmente teriam como resposta a definição de um elemento e de outro, sem que o aluno explicitasse as semelhanças e diferenças entre eles. Se isto for verdade, as questões dissertativas não estariam comprometidas com a aferição das habilidades mentais mais complexas, sendo mais uma forma de avaliar se os conteúdos foram memorizados/decorados pelos alunos, e não se foram, de fato, compreendidos de tal forma que possam ser remetidos a novas situações reais ou hipotéticas.

Em síntese, observou-se que, com relação à estruturação do pensamento mobilizado no total das questões analisadas, 78,26\% priorizavam a "repetição" ou memorização de um conceito, termo ou definição estudada (nível 1), 16,71\% procuravam a "integração" do conteúdo estudado à uma dada situação (nível 2) e apenas 5,02\% exigiam a "criação” por parte do aluno (nível 3).

Ao refletir sobre o tipo de avaliação que mais predominou neste estudo, pode-se dizer que elas pouco se aproximavam da avaliação formativa, segundo o que entendem Aydos et al. (2004) e Sant'Anna (1995), ambos referidos neste texto. Aydos et al. (2004) definem esse tipo de avaliação como aquele empregado durante o processo educacional, em seu momento intermediário. Para esses autores, a avaliação inicial (ou diagnóstica) e a somativa são empregadas no início e terminalização do processo educacional, respectivamente. Já para Sant'Anna (1995) esse tipo de avaliação é um método de determinar a aprendizagem do aluno. De acordo com a classificação desses autores, as avaliações analisadas neste trabalho teriam mais um caráter somativo do que diagnóstico ou formativo. Ainda que os professores quisessem tomá-las como um critério para avaliar o seu ensino, os tipos de questões propostas não favoreceriam a consecução deste objetivo. Nas questões do tipo memorístico, corre-se o risco de colocar no mesmo patamar de aprendizagem o aluno que compreendeu o assunto, o que "colou" a resposta e o que decorou, dificultando, pois, uma análise crítica do trabalho do professor a 
partir do estudo das respostas dadas pelos alunos às questões por ele formuladas.

Foi possível observar falhas técnicas na formulação de algumas perguntas das provas, sobretudo nas questões de "respostas curtas", "certo ou errado", "múltipla escolha" e "associação”. No primeiro caso, houve questões que forneciam pistas gráficas ao exigirem do aluno a complementação de lacunas de uma frase. As lacunas foram mal colocadas, transformando a pergunta em solução de um enigma. Isso pode ser verificado, por exemplo, na seguinte frase (questão) que apresenta duas lacunas antecedidas de pistas gráficas: "A transformação dessas formas do parasito no organismo do ocorre no

As questões de "certo ou errado" podem ser criticadas pelo apelo ao memorístico e, algumas vezes, pela ambigüidade das respostas. O mesmo ocorreu com as de "múltipla escolha", as quais, em sua maioria, seguiam um padrão mais ou menos assim: "o brotamento é um processo germinativo encontrado em" tais e tais grupos de animais. Quanto às questões de associação, detectou-se problemas como a presença de um mesmo número de opções e questões, o que elimina a possibilidade de avaliação integral do assunto exigido, uma vez que, ao fazer as relações, a última opção será sempre aquela que sobrou.

Tomando como referência as ênfases curriculares propostas por Moreira e Axt (1987), as questões formuladas, de um modo geral, veiculavam implicitamente uma ênfase curricular voltada às "explicações corretas", isto é, que concentra-se na transmissão dos produtos do conhecimento já aceitos pela comunidade de especialistas. Além dessa, talvez tenha sido veiculada a mensagem de uma ênfase na "fundamentação sólida", isto é, a de que o que o aluno está aprendendo se encaixa numa estrutura crescente e planejada. Pouco ou nada se enfatizou outras ênfases, como o "cotidiano" (os conhecimentos para entender e controlar os fenômenos ou problemas do dia-a-dia), ou a "estrutura do campo do conhecimento" (compreender como funciona a ciência, qual a natureza desse conhecimento), ou "conhecimento, tecnologia e sociedade" (o papel e as limitações do conhecimento científico para lidar com assuntos 
práticos), ou ainda as "habilidades" (a ênfase no uso dos processos básicos para se conhecer).

Com base nos mesmos autores, pode-se dizer que as provas analisadas sinalizam para concepções de currículo como "tecnologia”, isto é, como conhecimento transmitido, não questionado, cuja eficiência do ensino e aprendizagem se reduz à técnica instrucional, e também como "racionalismo acadêmico", por meio do qual se percebe o aluno como alguém que deve ser preparado para ter acesso ao conhecimento historicamente acumulado, na forma de disciplinas, e prioriza fortemente o conteúdo. Não se percebeu nas avaliações as concepções de currículo como "reconstrução social" (currículo que fornece elementos para que o aluno conviva com as mudanças no mundo e os prepara para intervir na formulação dessas mudanças), nem como "autorealização" (fortemente orientado para pensar os valores, o desenvolvimento pessoal), ou para o "desenvolvimento dos processos cognitivos" (focaliza o refinamento das operações intelectuais, desenvolvendo habilidades cognitivas, munindo o estudante de autonomia intelectual para interpretar situações que encontrará fora do contexto escolar).

Seriam essas as análises dos professores sobre o seu processo avaliativo? Como eles percebem as suas avaliações? São questões importantes a serem respondidas, pois, de acordo com Aydos et al. (2004) a autopercepção do professor sobre seu processo avaliativo proporciona um feed back do seu trabalho sobre os resultados do rendimento escolar do aluno.

A julgar pelo conteúdo das questões das provas analisadas, pode-se dizer que o processo avaliativo não é visto, pelos professores, como uma via de mão dupla, na qual tanto eles quanto os alunos são sujeitos da avaliação. No caso analisado, a avaliação é unilateral, isto é, refere-se somente ao aluno, tendo caráter normativo e não formativo, funcionando, apenas, como um "bisturi" por meio do qual seleciona-se os que dominam determinados conteúdos que, em sua maior parte, têm como exiĝencia intelectual apenas o esforço da memorização. Não se exige, portanto, o que destaca Hoffman (2000), que o aluno reflita sobre o mundo, que formule hipóteses e construa 
verdades, que aplique o conteúdo em situações do dia-a-dia, ou seja, que a avaliação exija uma consciência critica e responsável para solução de problemas.

\section{CoNSIDERAÇÕES FINAIS}

A formação de professores para a educação básica, deve dar o devido destaque à questão da avaliação nos seus fundamentos históricos, filosóficos e sociológicos e também nos seus aspectos propriamente técnicos, relativos ao "como" avaliar. Nesse sentido, os cursos de Licenciatura devem propiciar ao estudante a oportunidade de fundamentar e debater questões ligadas à avaliação escolar (o papel đa avaliação escolar, a relação entre avaliação e organização curricular, paradigmas e instrumentos de avaliação, aspectos conceituais e metodológicos) e questões específicas, relativas ao esse corpo de conhecimento a ser avaliado. Isso implica fundamentar o professor para avaliar o seu trabalho de formação do aluno para a aquisição de conhecimentos específicos, de habilidades, atitudes e competências necessárias ao pensamento crítico e científico. No caso das disciplinas relacionadas com as ciências da natureza, isso inclui a capacidade de análise e síntese, de comunicar-se oralmente e por escrito, de elaborar problemas de dominar instrumentos de aprender a aprender, de tomar decisões, de cumprir normas e procedimentos, de trabalhar em equipe, de observar, relatar, construir e interpretar gráficos, tabelas e quadros, comparar, supor, propor, consultar fontes de informação e criticar, dentre outras habilidades. Deve, ainda, preparar o graduando para desenvolver um currículo que inclua a realidade do aluno, enriquecendo e ampliando a sua visão sobre os desafios a ele impostos.

Acreditamos, ainda, que para propiciar a coerência entre a formação oferecida e a prática esperada, os currículos da formação do professor devem levar em conta a pesquisa como atividade nuclear do trabalho docente. Este deve ser compreendido numa perspectiva dinâmica, isto é, a formação do professor continua acontecendo na prática, após a conclusão legal do curso que the conferiu a habilitação. Nesse entendimento, o Estágio Supervisionado, como momento 
privilegiado de articulação entre teoria e prática, pode avançar e transformar em pesquisa a vivência do cotidiano da docência em sala de aula pelo estagiário. Em outras palavras, os estágios nos Cursos de Licenciatura devem preparar para exercício do magistério, assim como para a formação do futuro pesquisador nas suas respectivas áreas de atuação como professor.

No contexto específico em que se inseriu este trabalho - o de formação de professores de ciências e de biologia - procurou se preparar o futuro professor para o magistério e também para a pesquisa em Educação e Ciências, em especial, nas temáticas voltadas à reflexão sobre o papel da avaliação na prática docente.

Espera-se que, ao compreender o significado da sua ação, seja no ensino, seja na pesquisa, o professor possa utilizar os conhecimentos adquiridos para interpretar sua própria prática, interrogando-a e avançando na direção đa construção de um conhecimento pedagógico e também dos fundamentos da pesquisa em ensino e aprendizagem de ciências.

Este artigo representa um esforço nessa direção, pois se inseriu no programa de ensino da disciplina de Estágio Supervisionado, voltado à formação do professor de Biologia, que, dentre outros fundamentos, procurou compreender a avaliação como um elemento fundamental do processo educativo, percebendo-a na vertente formativa e emancipatória. Metodologicamente, este trabalho se fundamentou na idéia de que compreender as manifestações da prática avaliativa é, ao mesmo tempo, compreender aquilo que nela está oculto. Sendo assim, os resultados desta pesquisa forneceram elementos que auxiliaram a conhecer as concepções dos professores sobre a avaliação. A análise dos conteúdos das questões propostas nas provas, além de fornecer esses indicadores, proporcionou uma oportunidade de os acadêmicos vivenciarem a prática da pesquisa em ensino de ciências, trazendo preciosos elementos para a reflexão dos graduandos de biologia sobre o papel da avaliação, mais especificamente, do valor e dos limites das provas escritas na prática avaliativa. 


\section{REFERÊNCIAS}

AYDOS, A. P. B. R.; CARVALHAL, A. C. T.; FRANÇA, D. F.; SANTOS, M. F. V. A prática avaliativa na escola: que ação é essa? Monografia. Campo Grande (MS): UCDB, 2004.

FICHER, B. T. D. Processos Avaliativos: pano de fundo dos cenários escolares. Educação, São Leopoldo, จ. 6, n. 11, p. 11-27, 2002.

FREITAS, L. C. de. Crítica da organização do trabalho pedagógico e da didática. Campinas, SP: Papirus, 1995.

GIMENO-SACRISTÀN, J. El curriculum: una reflexión sobre la práctica. 5. ed. Madri : Morata, 1995.

HADJI, C. Avaliação demistificada. Porto Alegre: Artes Médicas, 2001.

HOFFMANN, J. Avaliação - Mitos \& Desafios: uma perspectiva construtiva. 28. ed. Porto Alegre: Mediação, 2000.

LIBÂNEO, J.C. Didática. 15. ed. São Paulo: Cortez, 1994.

LUCKESI, C. C. Avaliação da aprendizagem escolar: estudos e proposições. São Paulo: Cortez, 1995.

MACHADO, R. J. M. Questões dissertativas na avaliação escolar: o que considerar no preparo e aplicação. Revista do professor. จ. 7, n. 26, p. 22-5, abr./ jun. 1991.

MOREIRA, M. A.; AXT, R. Ênfases Curriculares e ensino de ciências. Ciência e Cultura, v. 39, n. 3, p. 250-258, 1987.

OLIVEIRA, A. M. S.; CRESPO, A. A. S.; OLIVEIRA, M. M. S.; LIMA, R. A. S. Avaliação. Monografia. Campo Grande (MS): UCDB, 2004.

PERRENOUD, P. Avaliação: da excelência à regulação das aprendizagens. Porto Alegre: Artmed, 1999.

10 novas competências para ensinar. Porto Aleogre: Artmed, 2000.

RAMOS, N. N. Perspectivas no trabalho em avaliação. AMAE Educando. Belo Horizonte, v. 20, n. 192, p. 41-3, nov. 1987.

RODRIGUES, J. Educação e Valores: Avaliação. Rio de Janeiro: Gazetilha, 1992.

SANT'ANNA, I. M. Porque Avaliar? Como Avaliar? Critérios e Instrumentos. Petrópolis: Vozes, 1995. 